\title{
Wear Behaviors of Stainless Steel and Lubrication Effect on Transitions in Lubrication Regimes in Sliding Contact
}

\author{
Yoon-Seok Lee ${ }^{1}$, Shunnosuke Yamagishi ${ }^{2}$, Masataka Tsuro ${ }^{2}$, Changwook $\mathrm{Ji}^{3}$, Seungchan Cho ${ }^{4}(\mathbb{D}$, \\ Yangdo Kim ${ }^{5, *}$ and Moonhee Choi ${ }^{1, *}$ \\ 1 Electronic Convergence Division, Korea Institute of Ceramic Engineering \& Technology (KICET), \\ Jinju 52851, Korea; yoonseok@kicet.re.kr \\ 2 Graduate School of Natural Science and Technology, Okayama University, Okayama 700-8530, Japan; \\ pj2m44hk@s.okayama-u.ac.jp (S.Y.); po1x8kuv@s.okayama-u.ac.jp (M.T.) \\ 3 Advanced Forming Process R\&D Group, Korea Institute of Industrial Technology, Ulsan 44413, Korea; \\ cwji@kitech.re.kr \\ 4 Composites Research Division, Korea Institute of Materials Science, Changwon 51508, Korea; \\ sccho@kims.re.kr \\ 5 Department of Materials Science and Engineering, Pusan National University, Busan 46241, Korea \\ * Correspondence: yangdo@pusan.ac.kr (Y.K.); moonhee77.choi@kicet.re.kr (M.C.)
}

Citation: Lee, Y.-S.; Yamagishi, S.; Tsuro, M.; Ji, C.; Cho, S.; Kim, Y.; Choi, M. Wear Behaviors of Stainless Steel and Lubrication Effect on Transitions in Lubrication Regimes in Sliding Contact. Metals 2021, 11, 1854. https://doi.org/10.3390/met11111854

Academic Editors: Angelo

Fernando Padilha and Guanyu Deng

Received: 30 September 2021

Accepted: 16 November 2021

Published: 18 November 2021

Publisher's Note: MDPI stays neutral with regard to jurisdictional claims in published maps and institutional affiliations.

Copyright: (c) 2021 by the authors. Licensee MDPI, Basel, Switzerland. This article is an open access article distributed under the terms and conditions of the Creative Commons Attribution (CC BY) license (https:// creativecommons.org/licenses/by/ $4.0 /)$.

\begin{abstract}
The wear behavior of AISI304 stainless steel was investigated under dry, water-, and oil-lubricated conditions. A block-on-disk wear test was conducted in this work, since the test conditions could be controlled easily. For oil-lubricated contact, a significant amount of thin and elongated cutting chip-like debris was observed. This is attributed to the high lubricating effect of oil. Strain-induced martensitic (SIM) transformation was observed for all AISI304 blocks after the wear test, while AISI30 4 consisted of a single $\gamma$-austenite phase prior to the wear test. The Stribeck curve and the corresponding lubrication regimes were also considered to explain the wear behaviors and lubrication effect of AISI304. In comparison to the dry or water-lubricated conditions, which fall in the boundary lubrication regime at a low rotation speed, it is considered that the high viscosity of the oil-based lubricant causes the lubrication condition to enter the mixed lubrication regime early at a lower speed, thus reducing the specific wear rate over the 100-300 rpm range.
\end{abstract}

Keywords: AISI304; martensitic transformation; austenite; lubricant; wear; friction; hydrodynamic lubrication

\section{Introduction}

Austenitic stainless steels are widely used in industrial fields owing to their superior ductility, high heat resistance, high corrosion resistance, and non-magnetic properties; however, they exhibit weak friction and wear properties [1,2]. When austenitic stainless steels come in contact with other steel-based materials with high metallurgical compatibility, severe wear may occur during the manufacturing processes such as sliding, drilling, and cutting, which, in turn, decrease the metal surface quality [3]; this is because metals with high metallurgical compatibility are highly soluble in their counterpart atom lattices. Therefore, these frictionally incompatible metals cause severe adhesive wear [4]. Several methods have been proposed to enhance the mechanical processability and operating efficiency, such as using lubricants to reduce the wear between contact surfaces under mechanical stress. Therefore, most mechanical machining processes of stainless steel are performed using water-based fluid or mineral oil [5].

In this study, a block-on-disk wear test was conducted owing to its relatively simple operation. In addition, compared to an actual machining test, the test conditions could be controlled easily [6]. Herein, AISI304, which is a widely used austenitic stainless steel, was used for the wear test under water- and oil-based lubricant contact conditions. Mineral oil, which is an oil-based lubricant that is extracted from petroleum, is commonly used in industrial fields. It contains chemicals such as paraffin and naphthene [7]. Although 
mineral oil lubricants are widely used in various industries, water-based lubricants are also attracting increasing attention [8].

In severe wear, the evolution of subsurface layer is observed along with that of the contact surface, thereby altering the mechanical properties of AISI304. Thus, studying the changes in the metallurgical microstructure is crucial for the applications of stainless steel. In these subsurface layers, strain-induced martensitic (SIM) transformations occur due to frictional stress, causing changes from $\gamma$-fcc to $\varepsilon$-hcp and $\alpha^{\prime}$-bcc phases $[3,9,10]$. Although a martensitic structure may increase the surface hardness, it decreases the corrosion resistivity, which leads to stress corrosion cracking. Moreover, wear debris is an important by-product that can be used to identify the machining conditions [11]. For example, wear behavior can be inferred from the amount of debris, size, shape, and composition [12-16]. Thus, the debris produced during the wear test was also sampled and analyzed.

In any industrial process, phenomena such as oxidative, abrasive, adhesive, and fatigue wear commonly occur. Thus, wear processes should be examined to understand the functionality of different parts under the combined wear conditions. Furthermore, to improve the wear resistance of stainless steel and expand its application scope, the metallurgical mechanisms, such as the lubrication effect with subsurface layers, should be investigated in detail, as research investigating wear behaviors based on metallurgy is still lacking. Therefore, research studies should focus on increasing the life cycle of parts, thereby allowing effective metal formation in industrial fields.

\section{Experimental Procedure}

\subsection{Materials}

AISI304 rod (C: 0.09, Si: 0.32, Mn: 1.29, P: 0.00, S: 0.15, Ni: 8.37, Cr: 20.32, and Fe: bal. mass \%) with a diameter of $10 \mathrm{~mm}$ was cut for using as a cylindrical block, as shown in Figure 1a. Furthermore, the AISI304 blocks were subjected to a solution treatment at $1373 \mathrm{~K}$ for $3600 \mathrm{~s}$ followed by water quenching. The Vickers hardness of the contact surfaces were also measured at a load of $9.8 \mathrm{~N}$ after heat treatment, which is the maximum load of the hardness tester (MVK-C, Akashi Co. Ltd., Takahama, Japan), for a holding time of $15 \mathrm{~s}$. Nine different points were measured for each block. The highest and lowest values were discarded, and the hardness of each block was determined using the average of the remaining seven values.

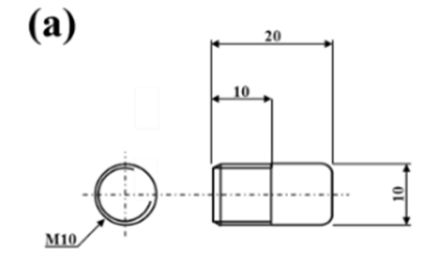

(c)
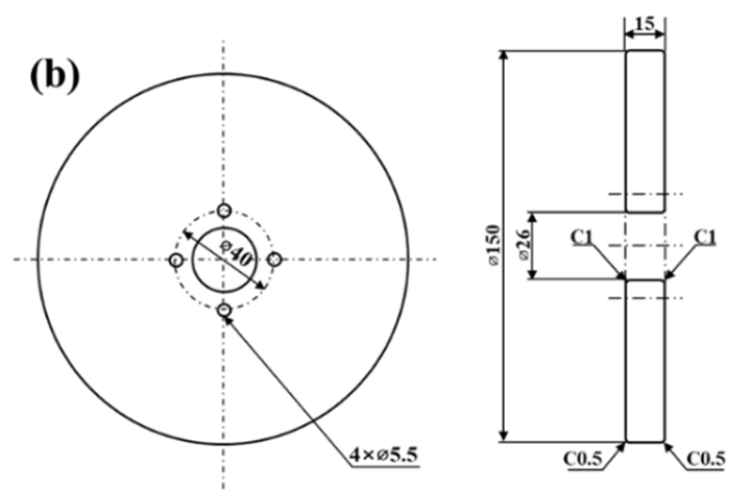

Figure 1. Specifications of (a) block, (b) disk, and (c) rod of experimental setup used for frictional wear test. 
Moreover, high speed steel (HSS) was used as a disk and a counter material in this wear-testing system, as shown in Figure $1 b, c$ exhibiting specification of the rod used for fixing the blocks and adding the normal load of $7.3 \mathrm{~N}$ to the blocks.

\subsection{Block-on-Disk Sliding Wear Test}

The block-on-disk wear-testing system was used in this study. The sliding wear is caused by a loaded block contacting a rotating disk. The wear tests were carried out in air at room temperature and constant humidity. The rotation speeds of the disk for each wear test were 100, 200, and $300 \mathrm{rpm}$, which indicates the sliding speeds of $0.79,1.57$, and $2.36 \mathrm{~mm} / \mathrm{s}$, respectively. Then AISI304 blocks were cleaned with acetone and dried in air in order to avoid contamination, before and after each wear test. The weight of each test block, before and after the wear test, was measured using a precise electric balance $(0.0001 \mathrm{~g})$. The wear weight loss $\left(W_{\text {loss }}\right)$ was obtained in grams from the following equation:

$$
W_{\text {loss }}=W_{2}-W_{1} \text {, }
$$

where $W_{1}$ and $W_{2}$ are respectively the weight of a block before and after the wear test. $W_{\text {loss }}$ can be converted into the volume loss $\left(V_{\text {loss }}\right)$ in $\mathrm{mm}^{3}$ using the following equation:

$$
V_{\text {loss }}=\frac{W_{\text {loss }}}{D_{\text {alloy }}}
$$

$D_{\text {alloy }}$ is the weight per unit volume for the density of AISI304 block (approximately $7.72 \mathrm{~g} / \mathrm{cm}^{3}$ ) obtained by calculations based on molecular weights. Then, the specific wear rate $\left(W_{\mathrm{s}}\right)$ was calculated using the following equation:

$$
W_{\mathrm{s}}=\frac{V_{\text {loss }}}{F_{\mathrm{n}} L}
$$

where $F_{\mathrm{n}}$ is the normal load applied in $\mathrm{N}$ and $L$ is the sliding distance in $\mathrm{m}$.

Most of the lubricants which are available in the market are based on mineral oils formulated from petroleum oil. In this study, the petroleum oil (n-butyl stearate $\leq 5$, sorbitan oleate $\leq 5$, and distillates: bal. mass $\%$ ) was also used as an oil-based lubricant in the wear-testing system.

\subsection{Analysis of Wear Characteristics}

The wear debris was sampled after the wear tests and analyzed using scanning electron microscopy (SEM, JIB-4500, JEOL Co. Ltd., Tokyo, Japan) combined with energydispersive spectroscopy (EDS). The wear tracks were also examined to understand the wear mechanisms.

Furthermore, some of the AISI304 blocks were sectioned parallel to the sliding direction to examine subsurface layers. SEM based electron back-scattered diffraction (EBSD) analysis was performed to develop a more quantitative view of deformation-induced nucleation of martensite in subsurface layers of the blocks. The cut surfaces were wet polished using $\mathrm{SiC}$ water proof papers and were subsequently buff-polished using an $\mathrm{Al}_{2} \mathrm{O}_{3}$ powder with an average diameter of $0.3 \mu \mathrm{m}$ and a colloidal $\mathrm{SiO}_{2}$ solution. The orientation data obtained from the EBSD scans were analyzed using an orientation imaging microscopy $\left(\mathrm{OIM}^{\mathrm{TM}}\right)$ analysis software (version 7.2, EDAX Inc., Mahwah, NJ, USA).

\section{Results and Discussion}

\subsection{Wear Behaviors and Characteristics}

When stainless steel was treated thermally and it became fully austenitic, the carbides, martensitic structure, and residual stress within the steel were removed, thereby improving its processability and corrosion resistivity. Therefore, to examine the microstructure of the thermally treated test block, its center of the contact surface was analyzed via EBSD prior 
to the wear test. As shown in Figure 2, the AISI304 sample comprised a single $\gamma$-austenite phase after heat treatment.
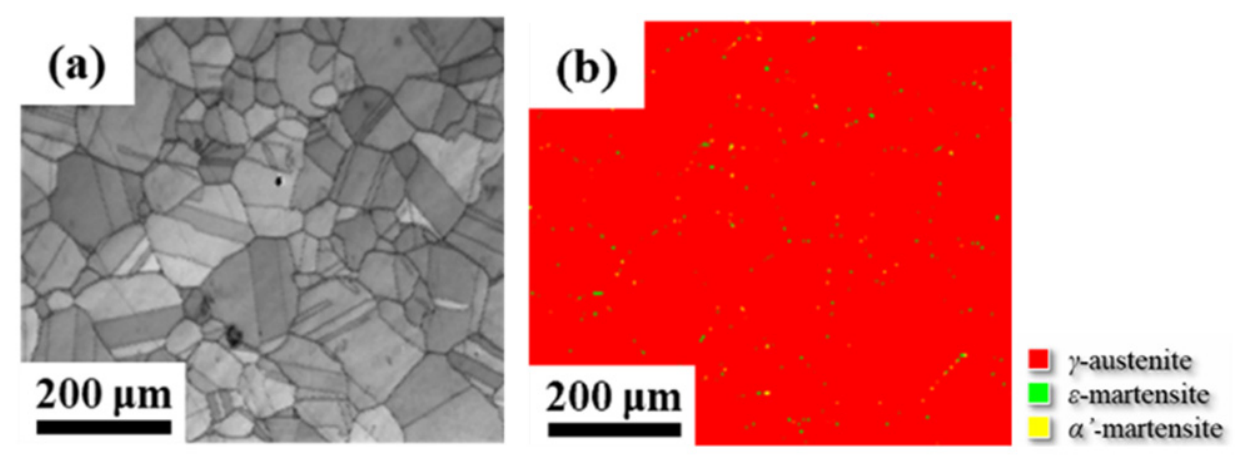

Figure 2. Electron back-scattered diffraction (EBSD) analysis of AISI304 blocks before wear test: (a) image quality (IQ) maps and (b) corresponding phase maps (PM).

The Vickers hardness of the post-treated AISI304 block was calculated as $150.3 \pm 4.47 \mathrm{HV}$; in contrast, the hardness value of its counterpart, HSS disk, was $678 \mathrm{HV}$, which is $~ 540 \mathrm{HV}$ higher than that of the AISI304 block. $W_{\mathrm{s}}$ for each test condition was calculated using Equations (1)-(3), as shown in Figure 3. At all the rotation speeds, $W_{\mathrm{s}}$ was the highest under dry conditions, followed by those under the water- and oil-lubricated conditions. Typically, under metal-to-metal contact, $W_{\mathrm{s}}$ is proportional to the sliding speed owing to frictional heat and adhesion. This behavior was observed under dry conditions, as shown in Figure 3. However, for the water-and oil-lubricated contacts at $300 \mathrm{rpm}$ and 200 and $300 \mathrm{rpm}$, respectively, $W_{\mathrm{s}}$ decreased. This is explained in the following sections.

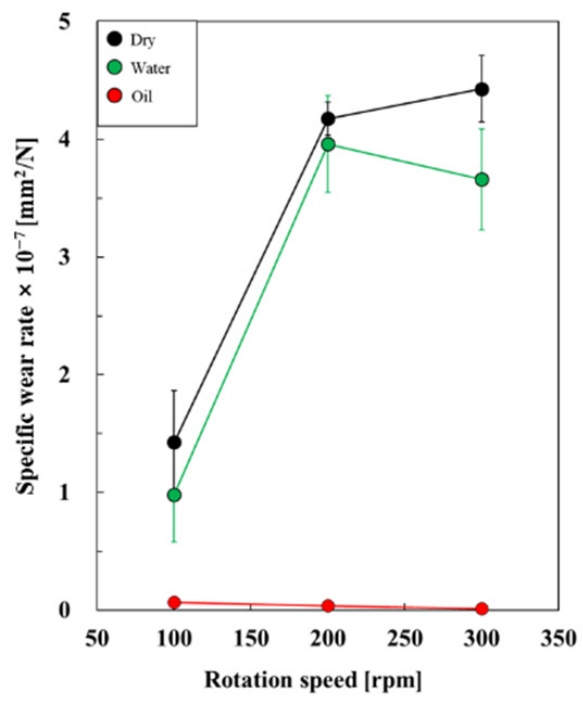

Figure 3. $W_{\mathrm{s}}$ of AISI304 blocks against HSS disk obtained from wear tests under dry, water-, and oil-lubricated conditions.

To understand the wear behavior and the mechanism through the wear tracks on the wear surfaces of the test blocks, SEM images were obtained, as shown in Figure 4. As shown in Figure $4 \mathrm{a}, \mathrm{b}$ for both low $(100 \mathrm{rpm})$ and high $(300 \mathrm{rpm})$ rotation speeds, the wear tracks of the test blocks under the dry condition showed a significant plastic deformation with smeared surfaces than those under water- and oil-lubricated conditions, thereby indicating strong adhesion forces during wear. In particular, at $300 \mathrm{rpm}$ (Figure $4 \mathrm{~b}$ ), numerous cracks had grown perpendicular to the slide direction, indicating that the fatigue wear causing subsurface cracks is also one of the major wear mechanisms. 

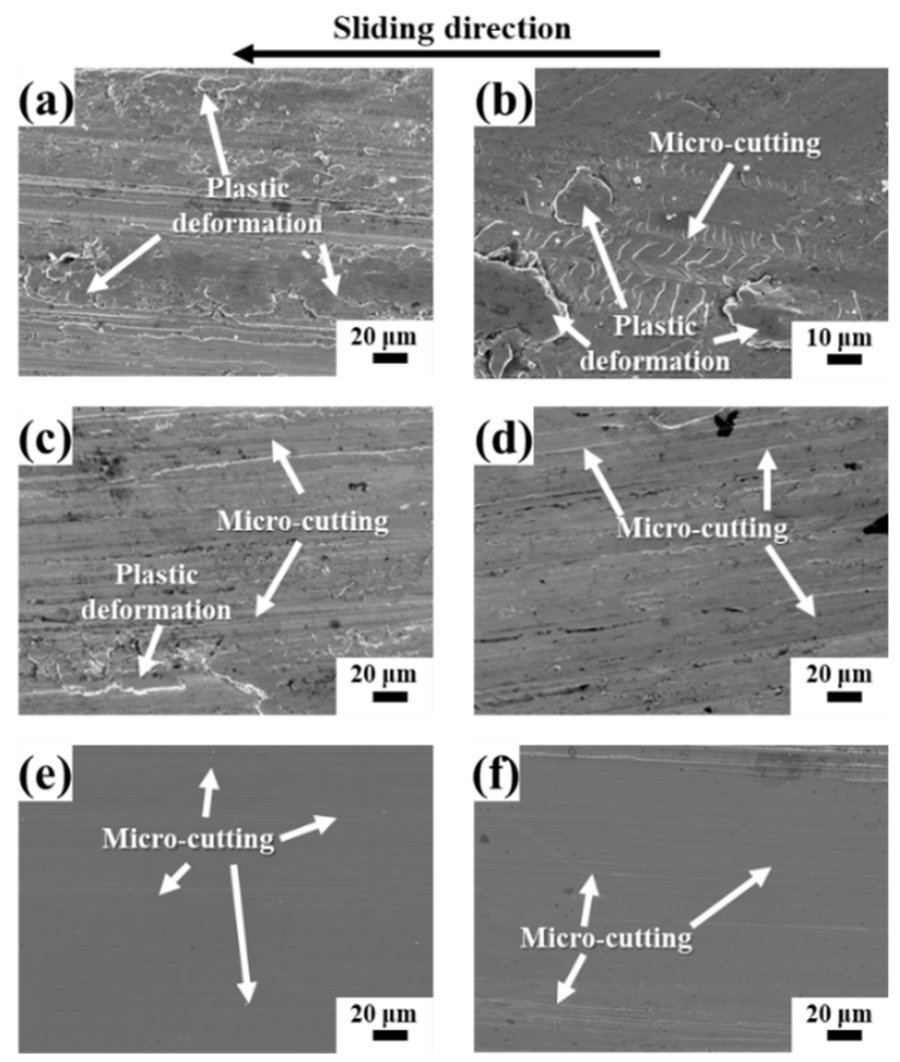

Figure 4. Scanning electron microscopy (SEM) micrographs of wear tracks on AISI304 blocks at rotation speeds of (a) 100 and (b) $300 \mathrm{rpm}$, obtained from tests under dry conditions, rotation speeds of (c) 100 and (d) $300 \mathrm{rpm}$, obtained from tests under water-lubricated conditions, and rotation speeds of (e) 100 and (f) $300 \mathrm{rpm}$, obtained from tests under oil-lubricated conditions.

Furthermore, micro-cutting plays a crucial role in the water-lubricated contact than that in the dry contact, which is a characteristic of abrasive wear. In the case of oil-lubricated contact, regular grooves with micro-cutting are more apparent. Furthermore, a significant decrease in severe plastic deformation was observed than the dry and water-lubricated contacts, regardless of the rotation speed, which confirms the presence of mild wear, indicating a dramatic reduction in the adhesion.

Both the disk and block comprise the same main chemical composition ( $\mathrm{Fe})$, demonstrating high metallurgical compatibility. Owing to the high metallurgical compatibility between the disk and block, strong adhesion is prone to occur during wear under the conditions used in this experiment. When water or oil is applied, a lubricating film is formed on the contact surface between the disk and block, decreasing the area of real contact $\left(A_{\mathrm{r}}\right)$. Adhesion occurs at the contact surface owing to the interatomic thermal interaction, and it decreases proportionally with $A_{\mathrm{r}}$. Thus, the decrease in shear stress reduces the plastic deformation of the contact surfaces, and micro-cutting is clearly observed, as shown in Figure $4 \mathrm{c}-\mathrm{f}$. In particular, for oil-lubricated contact, the plastic deformation is less severe on the wear tracks, suggesting that the lubricating effect of oil-based lubricant is greater than that of water-based lubricant.

As shown in Figure 5, the dry and water-lubricated contact produced significant amounts of irregular blocky and plate-like debris, clearly indicating fatigue wear [11,17-20]. In the oil-lubricated contact, a significant amount of thin and elongated cutting chip-like debris was observed; this is due to the harder asperities leaving micro-cutting grooves on the contact surface of the mating material that generates cutting chip-like debris. Furthermore, cutting chip-like debris confirms abrasive wear. Typically, while abrasive wear is known to have a higher $W_{\mathrm{s}}$ than other wear mechanisms, the oil-lubricated contact exhibits a low $W_{s}$, as shown in Figure 3. This is attributed to the high lubricating effect of oil, which 
causes much milder abrasive wear, as well as a decrease in the adhesive and fatigue wear. The EDS analysis was also carried out to analyze the wear debris. Strong peaks of chrome $(\mathrm{Cr})$ and nickel (Ni) are detected from debris under dry (Figure 6a,b) and other lubricated conditions, which indicates that they are from the test blocks rather than from the disk.
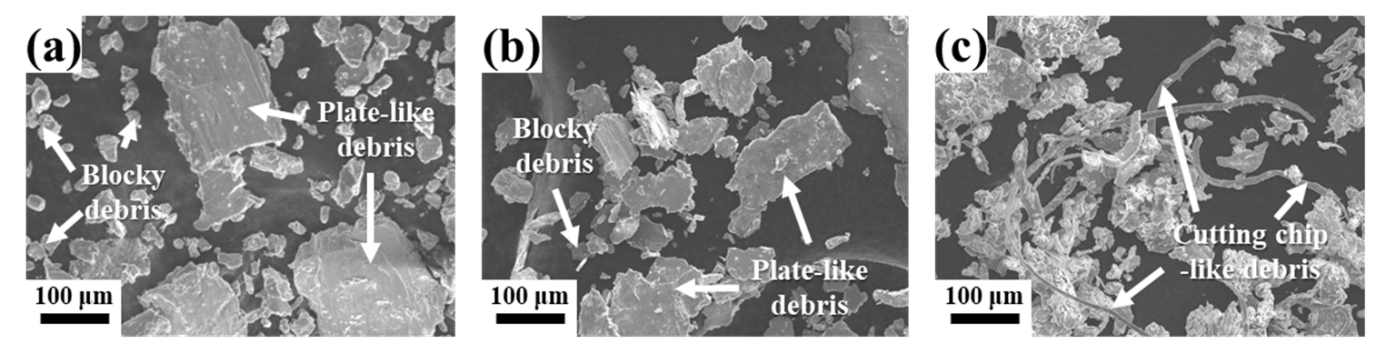

Figure 5. Morphologies of debris collected at the end of wear tests at a rotation speed of $200 \mathrm{rpm}$ and corresponding energy-dispersive X-ray spectroscopy (EDS) analysis; SEM micrographs of wear debris obtained under (a) dry, (b) water-, and (c) oil-lubricated conditions.

(a)

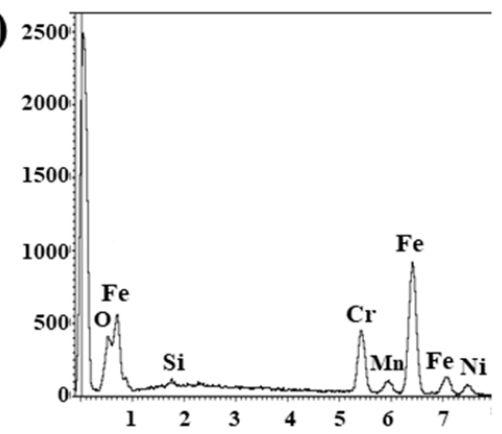

(b)

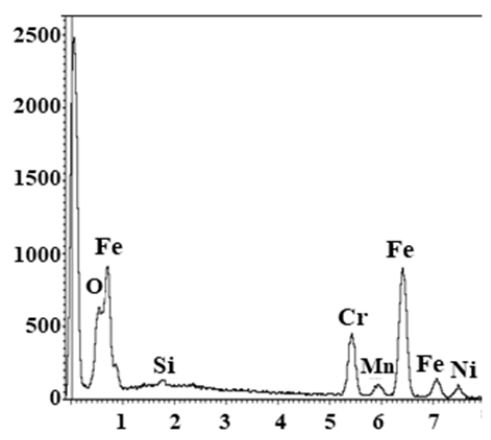

Figure 6. EDS analysis of (a) plate-like debris and (b) blocky debris collected at the end of wear tests at a rotation speed of $200 \mathrm{rpm}$ under dry contacts.

\subsection{Phase Transformation Behavior}

EBSD analysis was performed to observe the changes in the subsurface layer of the AISI304 block after each wear test, and the phase maps (PM) are shown in Figure 7. Similar to Figure 2, while AISI304 consisted of a single $\gamma$-austenite phase prior to the wear test, SIM transformation was observed for all blocks after the wear test.
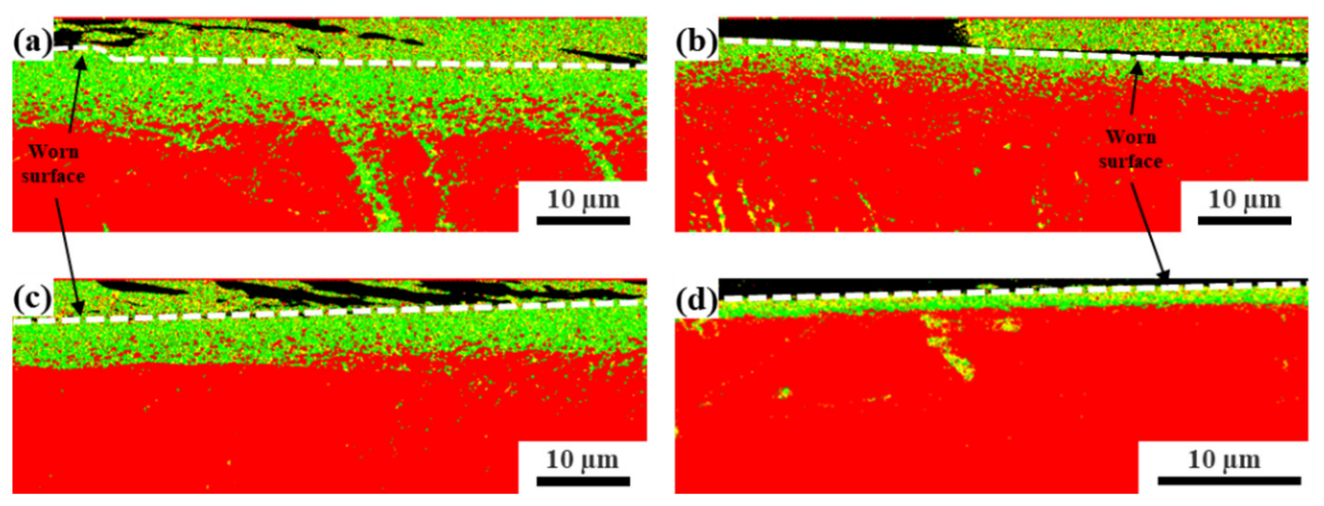

Figure 7. EBSD analysis of cross-sectioned AISI304 blocks after wear tests: phase maps of blocks at rotation speeds of (a) 100 and (b) $300 \mathrm{rpm}$ obtained from tests under dry contacts, (c) $300 \mathrm{rpm}$ obtained from tests under water-lubricated contacts, and (d) $300 \mathrm{rpm}$ obtained from tests under oil-lubricated contacts. 
It has been reported that high stacking fault energy (SFE) is strongly related to high austenite stability, which retards nucleation and growth SIM [21]. The SFE for austenitic stainless steel can be estimated through empirical equations, based on the chemical composition, using the following equation [22]:

$$
\mathrm{SFE}\left(\mathrm{mJ} / \mathrm{m}^{2}\right)=32+2.4(\% \mathrm{Ni})-1.2(\% \mathrm{Cr})-1.2(\% \mathrm{Mn})
$$

As SFE value increases, the dominant deformation mode is gradually shifted from $\varepsilon$-martensitic transformation to deformation twinning and then to slip [10]. The calculated SFE value is approximately $26 \mathrm{~mJ} / \mathrm{m}^{2}$ according to Equation (4), in this work. It is reported that the martensitic transformation in AISI304 can also occur at a higher SFE than around $20 \mathrm{~mJ} / \mathrm{m}^{2}$ [23], whereas deformation twinning is favored at SFE more than around $20 \mathrm{~mJ} / \mathrm{m}^{2}$ [24-26]. Furthermore, the SFE is mainly changed by variations in not only chemical composition but also deformation temperature [27-29]. The SFE increases with increasing deformation temperature with same chemical composition [23,28], which can retard nucleation and growth of strain-induced martensite.

In this study, no significant variance in the degree of SIM transformation with rotation speed was observed, excluding dry contact. Theoretically, the friction temperature is a function of the sliding speed. In the case of dry contact at $300 \mathrm{rpm}$, the frictional heat from high rotation speed caused an increase in the SFE, suppressing the SIM transformation. The high temperature is also responsible for the high adhesion and plastic shearing deformation, resulting in the highest $W_{\mathrm{s}}$, as shown in Figure 3.

In contrast, in the water-lubricated contact at $300 \mathrm{rpm}$, the water film at the contact surface can act as a coolant, decreasing the temperature from the frictional heat, resulting in a thicker martensite layer compared to the dry contact at $300 \mathrm{rpm}$. The oil-lubricated contact had the thinnest martensite layer $(\sim 1.5 \mu \mathrm{m})$, regardless of the rotation speed.

\subsection{Stribeck Curve and Lubrication Region}

An empirical criterion, the so-called Stribeck curve, is generally used to identify the three lubrication regimes [30]. Figure 8 shows a schematic of the Stribeck curve and the corresponding lubrication regimes, which are based on the viscosity $(\eta)$ and sliding speed $(V)$ under the same normal load. The Stribeck curve illustrates the relationship between the lubrication parameter and the basic trend of friction variation. Similar diagrams can easily be found in many books and articles [30,31]. The regime where $h \rightarrow 0$ is the boundary lubrication regime (I), and the regime to its right, where $h \approx R$ (surface roughness), is the mixed lubrication regime (II); herein, hydrodynamic, boundary, and solid lubrication are mixed. Finally, the regime, wherein $h>>R$, is the hydrodynamic lubrication regime (III).

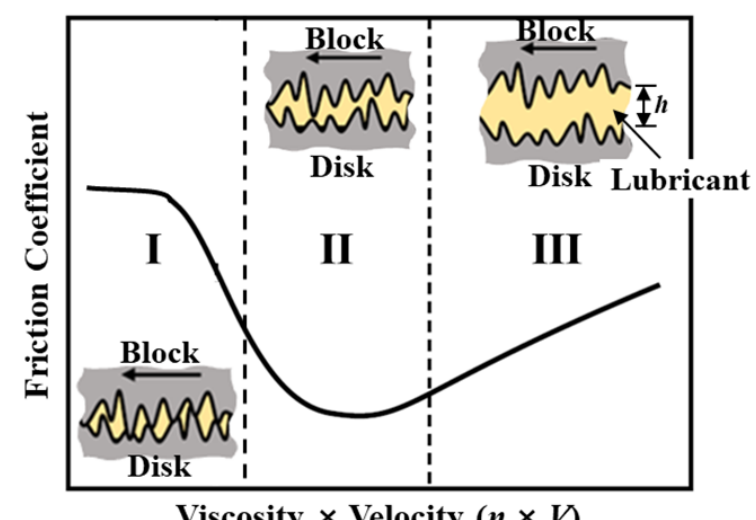

Figure 8. Schematic of the Stribeck curve showing three typical lubrication regimes.

As shown in Figure 3, unlike the dry contact, $W_{\mathrm{s}}$ decrease under the water-lubricated contact at $300 \mathrm{rpm}$. This may be attributed to the change in the lubrication regime from 
boundary (I) to the left side in the mixed lubrication regime (II) for the water-lubricated contact, as shown in Figure 8. Thus, at less than $200 \mathrm{rpm}$, the dry and water-lubricated conditions are both considered to be in the boundary lubrication regime (I), and no significant differences in both the friction coefficient and $W_{\mathrm{s}}$ were observed. The large plastic shear deformation in subsurface layer can lead to accumulation of shear strain and fatigue wear when strong adhesion exists at the contact area [17]. Therefore, in this region (below $200 \mathrm{rpm}$ under dry and water-lubricated conditions), $W_{\mathrm{s}}$ increases with increasing the rotation speed owing to the strong adhesion, although there is no sharp change in friction coefficient. However, above $200 \mathrm{rpm}$, under the water-lubricated condition, the lubrication regime shifts to the mixed lubrication regime (II), resulting in a significant change in $W_{\mathrm{s}}$ (Figure 3) with a sharp drop in friction coefficient (Figure 8). From the results described above, the amount of martensite at $300 \mathrm{rpm}$ is also larger under water-lubricated condition, compared to that under dry condition. It can be also explained by that shift in regime and a drop in friction coefficient.

Even at the same rotation speed, when the viscosity of the lubricant is sufficiently large, the Stribeck curve moves to the right. For the oil lubricant used herein, even at a low rotation speed (100 rpm), the lubricant is considered to be near or in the mixed lubrication regime (II). In comparison to the dry or water-lubricated conditions, which fall in the boundary lubrication regime (I) at a low speed (100 rpm), the high viscosity of the oil-based lubricant causes the lubrication condition to enter the mixed lubrication regime (II) early at a lower speed, thus reducing $W_{\mathrm{s}}$ over the 100-300 rpm range (Figure 3).

In conclusion, austenitic stainless steel can undergo various severe wear processes such as abrasive, adhesive, and fatigue wear during machining. In particular, when the counterpart material is rich in Fe, strong adhesion may occur, resulting in SIM transformations and subsurface shear deformation. The SIM transformation decreases the corrosion resistance and causes stress corrosion cracking. To prevent this, various water-based and oil-based lubricants are used in drilling and cutting processes. Studies on wear properties, adhesion of contact surfaces, and subsurface deformation under different lubrication conditions can provide fundamental knowledge for machining process applications.

\section{Conclusions}

In this study, the wear characteristics and behaviors of AISI304 austenitic stainless steel were evaluated at the different rotation speeds, under dry, water-, and oil-lubricated conditions. The primary findings of this study are the following:

1. Owing to the high metallurgical compatibility between the disk and block, strong adhesion is prone to occur during wear. When water or oil is applied, a lubricating film is formed on the contact surface, decreasing $A_{\mathrm{r}}$ and adhesion.

2. In the oil-lubricated contact, a significant amount of thin and elongated cutting chiplike debris was observed. This is attributed to the high lubricating effect of oil, which causes mild abrasive wear.

3. In the water-lubricated contact at $300 \mathrm{rpm}$, the water film at the contact surface acted as a coolant, decreasing the temperature from the frictional heat, resulting in a thicker martensite layer compared to the dry contact at $300 \mathrm{rpm}$.

4. At less than $200 \mathrm{rpm}$, the dry and water-lubricated conditions are both considered to be in the boundary lubrication regime, and no significant differences in both the friction coefficient and $W_{\mathrm{s}}$ were observed. However, above $200 \mathrm{rpm}$, under the waterlubricated condition, the lubrication regime shifts to the mixed lubrication region, resulting in a significant change in $W_{\mathrm{s}}$.

5. In comparison to the dry or water-lubricated conditions, which fall in the boundary lubrication regime at a low rotation speed (100 rpm), the high viscosity of the oil-based lubricant causes the lubrication condition to enter the mixed lubrication regime early at a lower speed, thus reducing $W_{\mathrm{s}}$ over the 100-300 rpm range. 
Author Contributions: Conceptualization, Y.-S.L.; methodology, Y.-S.L.; formal analysis, S.Y. and M.T.; investigation, S.Y., M.T., C.J. and S.C.; resources, S.Y. and M.T.; data curation, Y.-S.L., S.Y., M.T., C.J. and S.C.; writing—original draft preparation, Y.-S.L.; writing—review and editing, Y.K. and M.C.; visualization, Y.-S.L., S.Y. and M.T.; supervision, Y.K.; project administration, Y.K. and M.C.; Funding acquisition, M.C. All authors have read and agreed to the published version of the manuscript.

Funding: This work was supported by Institute for Information and communications Technology Promotion (IITP) grant funded by the Korea government (MSIP) (No.2021-0-00793).

Institutional Review Board Statement: Not applicable.

Informed Consent Statement: Not applicable.

Data Availability Statement: Not applicable.

Conflicts of Interest: The authors declare no conflict of interest.

\section{References}

1. Wei, X.; Hua, M.; Xue, Z.; Gao, Z.; Li, J. Evolution of friction-induced microstructure of SUS 304 meta-stable austenitic stainless steel and its influence on wear behavior. Wear 2009, 267, 1386-1392. [CrossRef]

2. Lamberson, L.; Mates, S.; Eliasson, V. Dynamic Behavior of Materials; Springer: Cham, Switzerland, 2020 ; Volume 1.

3. McEvily, A.J.; Velazquez, J.L.G. Fatigue crack tip deformation. Metall. Trans. A 1992, 23, 2211-2221. [CrossRef]

4. Rabinowicz, E. Friction and Wear of Materials, 2nd ed.; Wiley: New York, NY, USA, 1995.

5. Junior, A.B.; Diniz, A.E.; Filho, F.T. Tool wear and tool life in end milling of 15-5 PH stainless steel under different cooling and lubrication conditions. Int. J. Adv. Manuf. Technol. 2009, 43, 756-764. [CrossRef]

6. Xingzhong, Z.; Jiajun, L.; Baoliang, Z.; Hezhou, M.; Zhenbi, L. Wear behavior of Si3N4 ceramic cutting tool material against stainless steel in dry and water-lubricated conditions. Ceram. Int. 1999, 25, 309-315. [CrossRef]

7. Salih, N.; Salimon, J.; Yousif, E. Synthetic biolubricant basestocks based on environmentally friendly raw materials. J. King Saud Univ. Sci. 2012, 24, 221-226. [CrossRef]

8. Higdon, C.; Cook, B.; Harringa, J.; Russell, A.; Goldsmith, J.; Qu, J.; Blau, P. Friction and wear mechanisms in AlMgB14-TiB2 nanocoatings. Wear 2011, 271, 2111-2115. [CrossRef]

9. Fiedler, H.C. The effect of deformation on the martensitic transformation in austenitic stainless steels. Trans. ASM 1955, 47, 267-290.

10. Choi, J.-Y.; Jin, W. Strain induced martensite formation and its effect on strain hardening behavior in the cold drawn 304 austenitic stainless steels. Scr. Mater. 1997, 36, 99-104. [CrossRef]

11. Hong, W.; Cai, W.; Wang, S.; Tomovic, M.M. Mechanical wear debris feature, detection, and diagnosis: A review. Chin. J. Aeronaut. 2018, 31, 867-882. [CrossRef]

12. Seifert, W.W.; Westcott, V.C. A method for the study of wear particles in lubricating oil. Wear 1972, 21, 27-42. [CrossRef]

13. Dowson, D.; Dalmaz, G.; Childs, T.; Taylor, C.; Godet, M. Wear Particles: From the Cradle to the Grave; Elsevier: Amsterdam, The Netherlands, 1992.

14. Roylance, B.; Raadnui, S. The morphological attributes of wear particles—their role in identifying wear mechanisms. Wear 1994, 175, 115-121. [CrossRef]

15. Eisentraut, K.J.; Newman, R.W.; Saba, C.S.; Kauffman, R.E.; Rhine, W.E. Spectrometric oil analysis. Detecting engine failures before they occur. Anal. Chem. 1984, 56, 1086A-1094A. [CrossRef]

16. Bharath, V.; Auradi, V.; Nagaral, M.; Boppana, S.B.; Ramesh, S.; Palanikumar, K. Microstructural and Wear Behavior of Al2014Alumina Composites with Varying Alumina Content. Trans. Indian Inst. Met. 2021, 56, 1-15. [CrossRef]

17. Suh, N.P. An overview of the delamination theory of wear. Wear 1977, 44, 1-16. [CrossRef]

18. Wilson, S.; Alpas, A.T. Thermal effects on mild wear transitions in dry sliding of an aluminum alloy. Wear 1999, 225, 440-449. [CrossRef]

19. Zhang, J.; Alpas, A.T. Delamination wear in ductile materials containing second phase particles. Mater. Sci. Eng. A 1993, 160, 25-35. [CrossRef]

20. Ashok Raj, J.; Kailas, S.V. Evolution of wear debris morphology during dry sliding of Ti-6Al-4V against SS316L under ambient and vacuum conditions. Wear 2020, 456, 203378.

21. Talonen, J.; Hänninen, H. Formation of shear bands and strain-induced martensite during plastic deformation of metastable austenitic stainless steels. Acta Mater. 2007, 55, 6108-6118. [CrossRef]

22. Schramm, R.E.; Reed, R.P. Stacking fault energies of seven commercial austenitic stainless steels. Metall. Trans. A 1975, 6, 1345. [CrossRef]

23. Noh, J.H.; Lee, S.G.; Park, H.; Kang, N. Effect of Composition on Strain-Induced Martensite Transformation and Tensile Stress-Strain Curve for Austenitic Stainless Steels. J. Weld. Join. 2018, 36, 28-33. [CrossRef]

24. Olson, G.B.; Cohen, M. A general mechanism of martensitic nucleation: Part I. General concepts and the FCC $\rightarrow$ HCP transformation. Metall. Trans. A 1976, 7, 1897-1904. 
25. Allain, S.; Chateau, J.P.; Bouaziz, O. A physical model of the twinning-induced plasticity effect in a high manganese austenitic steel. Mater. Sci. Eng. A 2004, 387, 143-147. [CrossRef]

26. Curtze, S.; Kuokkala, V.T.; Oikari, A.; Talonen, J.; Hänninen, H. Thermodynamic modeling of the stacking fault energy of austenitic steels. Acta Mater. 2011, 59, 1068-1076. [CrossRef]

27. Saeed-Akbari, A.; Mosecker, L.; Schwedt, A.; Bleck, W. Characterization and prediction of flow behavior in high-manganese twinning induced plasticity steels: Part I. Mechanism maps and work-hardening behavior. Metall. Mater. Trans. A 2012, 43, 1688-1704. [CrossRef]

28. Walter, M.; Roncery, L.M.; Weber, S.; Leich, L.; Theisen, W. XRD measurement of stacking fault energy of Cr-Ni austenitic steels: Influence of temperature and alloying elements. J. Mater. Sci. 2020, 55, 13424-13437. [CrossRef]

29. Mosecker, L.; Pierce, D.T.; Schwedt, A.; Beighmohamadi, M.; Mayer, J.; Bleck, W.; Wittig, J.E. Temperature effect on deformation mechanisms and mechanical properties of a high manganese $\mathrm{C}+\mathrm{N}$ alloyed austenitic stainless steel. Mater. Sci. Eng. A 2015, 642, 71-83. [CrossRef]

30. Kadokawa, J. Ionic Liquids: New Aspects for the Future; InTech: Rijeka, Croatia, 2013.

31. Williams, J.A. Engineering Tribology; Oxford University Press: Oxford, UK, 1994. 